UCRL- 100237

PREPRINT

\title{
INTERACTIVE PRE AND POST-PROCESSING TOOLS FOR FINITE-DIFFERENCE TIME-DOMAIN CODES
}

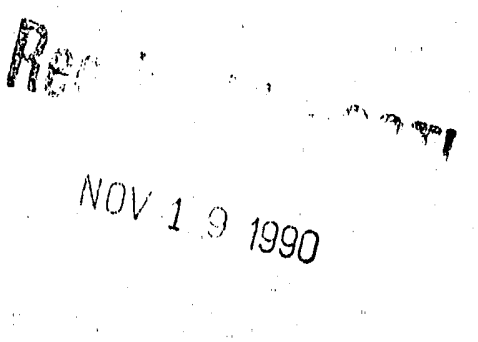

\author{
B. K. Cabral \\ G. W. Laguna \\ R. R. McLeod \\ S. L. Ray \\ S. T. Pennock \\ R. L. Berger \\ M. F. Bland
}

This paper is being prepared for submittal to the IEEE 1989 AP-S

International Symposium

San Jose, California

June 26-30, 1989

January 12, 1989

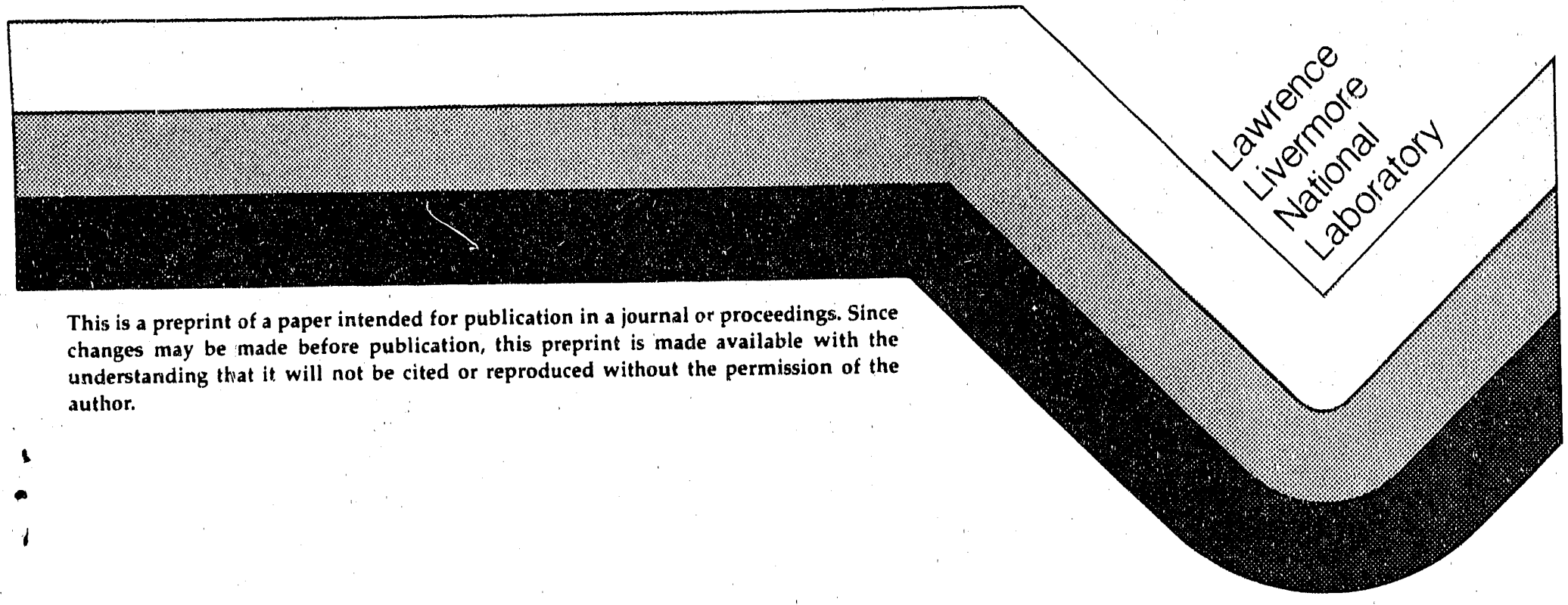

\section{MASTER}




\section{DISCLAIMER}

This document was prepared as an account of work sponsored by an agency of the United Stutes Government. Neither the United States Government nor the University of California nor any of their employees, makes any warranty, express or implied, or assumes any legal liability or responsibility for the accuracy, completeness, or usefulness of any information, apparatus, product, or process disclosed, or represents that its use would not infringe privately owned rights. Reference herein to any specific commercial products, process, or service by trade name, trademark, manufacturer, or othurwise, does not necessarily constitute or imply its endorsement, recommendation. or favoring by the Linited Stutes Government oi the University of California. The views and opinions of authors expressed hercin do not necessarily state or reflect those of the United States Government or the University of California, and shall not be used for advertising or product endorsement purposes. 


\author{
B. K. Cabral, G. W. Laguna, R. R. Mcleod, \\ S. L. RAY*, S. T. PenNock, R. L. Berger, M. F. Bland \\ Lawrence Livermore National Laboratory \\ P. O. Box 5504, L-156, Livermore, CA 94550
}

\title{
I. INTRODUCTION
}

Practical three-dimensional electromagnetic modeling has traditionally been hampered by insufficient computing power. Recent advances in computer hardware are beginning to remove this difficulty, and one can expect that this trend will continue for the forseeable future. To exploit this increased computer power and to solve more realistic problems, researchers have developed numerous algorithms appropriate for 3-D calculations and have built large general-purpose computer codes around them. In spite of this technical and theoretical progress, two practical difficulties remain: providing the computer code with an accurate description of a particular problem (pre-processing) and viewing the end results of the calculation (post-processing). These become daunting tasks for all but the simplest of problems in 3-D due to the large amount of data involved.

Researchers at the Lawrence Livermore National Laboratory have been developing and using a new finite-difference, time-domain (FDTD) [1] code over the last few years. This code, TSAR [2], is currently being used on a wide range of electromagnetic scattering, coupling, and propagation problems. Some of the geometries of interest are large and quite detailed, requiring meshes with more than a million cells. In addition, an FDTD code is often run for thousands of time steps, producing an enormous quantity of output data.

To efficiertly deal with these large problems, we have developed a set of pre and postprocessing tools to be used in conjunction with the TSAR FDTD code. This set of utilities consists of a solid-model based mesh generator, a mesh verifier, and a color/surface plotter. These tools all run on graphics workstations and, due to their highly interactive nature, are quite easy to use. For added convenience, some of the workstations are connected to a videotape system. With this arrangement, users can record complex time-varying results in a convenient and portable format. We anticipate that the poster talk associated with this paper will include a videotape demonstration of these capabilities.

\section{Mesh Generation}

In the past, FDTD meshes were constructed by hand or by using tresh construction codes with limited capabilities. While these approaches are sufficient for simple objects, they become tedious, labor intensive, and error prone when applied to large, complex structures. In an effort to streamline the gridding process and improve its accuracy, we have been developing an automatic mesh generator based on a solid modeling approach $[3,4]$. In this technique, the user builds a mathematically precise representation of the

This work was performed by the Lawrence Livermore National Laboratory under the auspices of the U. S. Department of Energy under contract W-T405-ENG-48. 
undiscretized object using a solid modeling program [5]. A special-purpose mesh generation code, MGFD, has then been developed which operates on the solid-model database to automatically produce an FDTD grid. The code attempts to take into account the spatially-staggered nature of the FDTD mesh and the vector nature of the unknowns. This approach has a number of advantages over earlier methods. First, it is faster and more reliable. Second, users build their models once, independent of cell size; if a finer mesh is required, only the mesh generation program needs to be rerun. Finally, it provides a means of true mesh generation as opposed to mesh construction.

\section{MESH VERIFICATION}

FDTD code users need to be able to view and inspect their models to verify that the grid accurately represents the object under study. This need is independent of whether the input mesh was developed by hand or by an automated program such as that described above; any mesh generation method has the potential for inadvertently modifying the geometry, either by operator error or by some idiosyncrasy of the mesh generation code. Additionally, FDTD mesh discretization is inherently non-unique. Some user interaction is often required to develop an appropriate mesh.

To aid in mesh verification, we have developed an interactive visualization code called IMAGE [3]. With this code running on a high-end color workstation, users can rotate, slice through, and zoom in on various portions of their meshes in near real-time. In addition, various materials and/or field components can be displayed in different colors or erased to aid in the inspection of a complex mesh. The code is quite easy to use due to its mouse/software button user interface and has proven to be essential when applying the FDTD method to non-trivial objects.

\section{Interactive Post-Processing}

A variety of post-processing utilities have also been developed for use with TSAR. One code in particular, SURFACE, is highly interactive and workstation based. This code allows the user to display a 2-D slice of data either as a surface plot or as a color fringe plot. Two dependent variables (i.e., two different components of the electric field) can be displayed simultaneously using both color and height. As with IMAGE, SURFACE uses a mouse/button user interface, allowing the user to change the orie.station of the plot readily. Similarly, alternate data sets (i.e., other dependent variables, 2-D slices, and/or time steps) can be displayed easily.

\section{REFERENCES}

[1] Yee, K. S., "Numerical solution of initial boundary value problems involving Maxwell's equations in isotropic media," IEEE Trans. Antennas Propagat., vol. AP-14, pp. 302-307, May 1966.

[2] McLeod, R. R., "Temporal Scattering and Reflection ('TSAR) Software: users' manual," Internal report, Lawrence Livermore National Laboratory, Livermore, CA, September 1987.

[3] Laguna, G. W., White, T. W., and Cabral, B. K., "Generating meshes for finite difference analysis using a solid modeler," UCID-21189, Lawrence iivermore National Laboratory, Livermore, CA, September 1987.

[4] Laguna, G. W., "The generation of meshes for finite difference analysis from a solid model data base," Proceedings of the 1988 BRL-CAD Symposium, Aberdeen, MD, June 28-29, 1988.

[5] Muuss, M. J., et al., "Ballistics Research Laboratcry CAD package, resease 1.21," Internal report, Ballistics Research Laboratory, Aberdeen, MD, June 1987. 

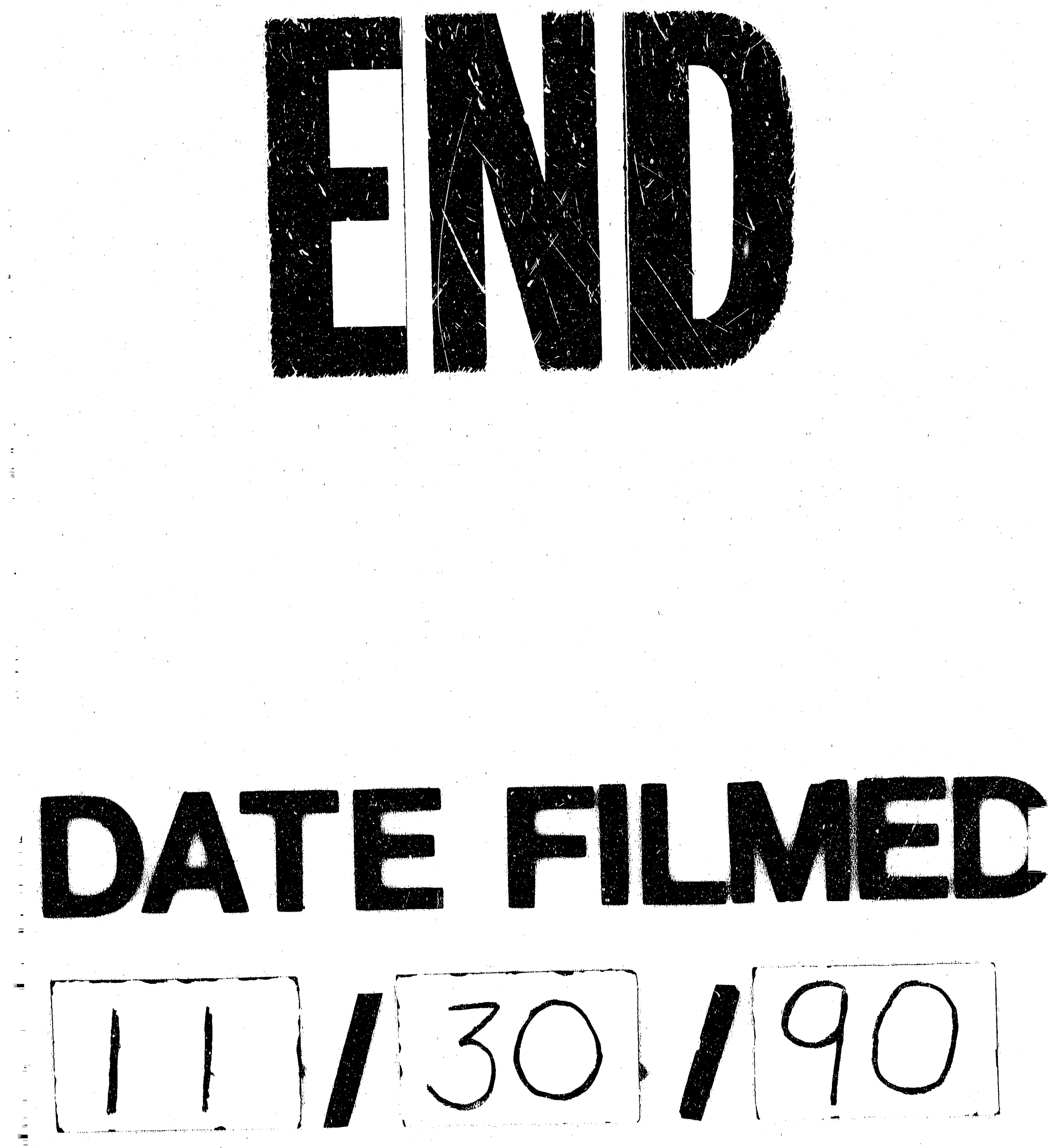
